\title{
Cardioprotective Strategy for Patients With Nonmetastatic Breast Cancer Who Are Receiving an Anthracycline-Based Chemotherapy A Randomized Clinical Trial
}

\author{
Lorenzo Livi, MD; Giuseppe Barletta, MD; Francesca Martella, MD; Calogero Saieva, MD; Isacco Desideri, MD; Carlotta Bacci, MD; \\ Maria Riccarda Del Bene, MD; Mario Airoldi, MD; Domenico Amoroso, MD; Luigi Coltelli, MD; Vieri Scotti, MD; Carlotta Becherini, MD; \\ Luca Visani, MD; Viola Salvestrini, MD; Matteo Mariotti; Fulvia Pedani, MD; Marco Bernini, MD, PhD; Luis Sanchez, MD; Lorenzo Orzalesi, MD; \\ Jacopo Nori, MD; Simonetta Bianchi, MD; lacopo Olivotto, MD, PhD; Icro Meattini, MD
}

IMPORTANCE Several studies have evaluated cardioprotective strategies to prevent myocardial dysfunction in patients who are receiving cardiotoxic therapies. However, the optimal approach still represents a controversial issue.

OBJECTIVE To determine whether pharmacological cardioprevention could reduce subclinical heart damage in patients with breast cancer who are being treated with anthracycline-based chemotherapy.

DESIGN, SETTING, AND PARTICIPANTS The SAFE trial was a 4-arm, randomized, phase 3 , double-blind, placebo-controlled, national multicentric study conducted at 8 oncology departments in Italy. It was a prespecified interim analysis on the first 174 patients who had completed cardiac assessment at 12 months. The study recruitment was conducted between July 2015 and June 2020. The interim analysis was performed in 2020. Patients were eligible for trial inclusion if they had indication to receive primary or postoperative systemic therapy using an anthracycline-based regimen. Patients with a prior diagnosis of cardiovascular disease were excluded.

INTERVENTIONS Cardioprotective therapy (bisoprolol, ramipril, or both drugs compared with placebo) was administered for 1 year from the initiation of chemotherapy or until the end of trastuzumab therapy in case of ERBB2-positive patients. Doses for all groups were systematically up-titrated up to the daily target dose of bisoprolol (5 mg, once daily), ramipril ( $5 \mathrm{mg}$, once daily), and placebo, if tolerated.

MAIN OUTCOMES AND MEASURES The primary end point was defined as detection of any subclinical impairment (worsening $\geq 10 \%$ ) in myocardial function and deformation measured with standard and 3-dimensional (3D) echocardiography, left ventricular ejection fraction (LVEF), and global longitudinal strain (GLS).

RESULTS The analysis was performed on 174 women (median age, 48 years; range, 24-75 years) who had completed a cardiological assessment at 12 months and reached the end of treatment. At 12 months, 3D-LVEF worsened by $4.4 \%$ in placebo arm and 3.0\%, 1.9\%, $1.3 \%$ in the ramipril, bisoprolol, ramipril plus bisoprolol arms, respectively $(P=.01)$. Global longitudinal strain worsened by $6.0 \%$ in placebo arm and $1.5 \%$ and $0.6 \%$ in the ramipril and bisoprolol arms, respectively, whereas it was unchanged ( $0.1 \%$ improvement) in the ramipril plus bisoprolol arm $(P<.001)$. The number of patients showing a reduction of $10 \%$ or greater in 3D-LVEF was 8 (19\%) in the placebo arm, $5(11.5 \%)$ in the ramipril arm, $5(11.4 \%)$ in the bisoprolol, arm and $3(6.8 \%)$ in the ramipril plus bisoprolol arm; 15 patients (35.7\%) who received placebo showed a $10 \%$ or greater worsening of GLS compared with 7 (15.9; ramipril), 6 (13.6\%; bisoprolol), and 6 (13.6\%; ramipril plus bisoprolol) $(P=.03)$.

CONCLUSIONS AND RELEVANCE The interim analysis of this randomized clinical trials suggested that cardioprotective pharmacological strategies in patients who were affected by breast cancer and were receiving an anthracycline-based chemotherapy are well tolerated and seem to protect against cancer therapy-related LVEF decline and heart remodeling.

TRIAL REGISTRATION ClinicalTrials.gov identifier: NCT2236806

JAMA Oncol. doi:10.1001/jamaoncol.2021.3395

Published online August 26, 2021.
Supplemental content

Author Affiliations: Author affiliations are listed at the end of this article.

Corresponding Author: Icro Meattini, MD, Department of Experimental and Clinical Biomedical Sciences, University of Florence, Viale Morgagni 50, 50134 - Florence, Italy (icro.meattini@unifi.it). 
$\mathrm{F}$ or decades, anthracycline-based chemotherapy regimens have been a mainstay in treating breast cancer (BC). ${ }^{1}$ However, anthracyclines may result in mild or severe short- and long-term toxic effects, with cardiotoxic effects being a well-known complication. ${ }^{2,3}$ Reduced left ventricular ejection fraction (LVEF) leads to interruption or discontinuation of therapy and is associated with an increased death risk. ${ }^{4}$

Echocardiography is considered the criterion standard in the cardiac imaging evaluation of patients during and after cancer therapy. ${ }^{5}$ Remodeling that precedes ventricular dysfunction and a reduction in global linear strain (GLS) seems to be the most sensitive parameter to predict early cardiotoxic effects. ${ }^{6,7}$

Angiotensin-converting enzyme inhibitors (ACEis)/ angiotensin-II receptor blockers and $\beta$-blockers (BB) have been shown to prevent cardiac remodeling and reduce mortality in patients with cardiac dysfunction ${ }^{8}$ and have been proposed for cardioprotection in oncology. ${ }^{9}$ In this article, we examine the results of the preplanned interim analysis of the SAFE phase 3 randomized clinical trial that assessed a cardioprotective strategy in preventing subclinical cardiac damage caused by anthracycline-based chemotherapy.

\section{Methods}

SAFE (NCT2236806) was a 4-arm, randomized, phase 3, double-blind, placebo-controlled study that aimed to evaluate the effect of bisoprolol, ramipril, or both drugs compared with placebo on subclinical cardiac dysfunction that was evaluated by 3-dimensional (3D) and speckle tracking cardiac echocardiography in patients with nonmetastatic BC (Supplement 1). The trial was approved by the local and national ethical committees and participants provided written informed consent. Cardioprotective therapy was administered for 1 year from the initiation of chemotherapy or until the end of trastuzumab therapy. The primary end point was defined as detection of any subclinical impairment (worsening $\geq 10 \%$ ) in myocardial function and deformation measured with standard and 3D echocardiography, LVEF, and GLS. Doses for all groups were up titrated at 1-week intervals up to the target dose of bisoprolol (5 mg), ramipril (5 mg), and placebo, if tolerated. All patients underwent cardiac surveillance at baseline (TO), 3

\section{Key Points}

Question Can pharmacological cardioprevention avoid subclinical damage in patients with breast cancer who are undergoing cardiotoxic therapy?

Findings In this randomized clinical trial of 262 patients with breast cancer, 174 of whom were analyzed, at 12 months, left ventricular ejection fraction as evaluated by 3-dimensional echocardiography worsened by $4.4 \%$ in the placebo arm and $3 \%$, $1.9 \%, 1.3 \%$ in the ramipril, bisoprolol, and ramipril plus bisoprolol arms, respectively. Global longitudinal strain worsened by $6.0 \%$ in the placebo arm and $1.5 \%$ and $0.6 \%$ in the ramipril and bisoprolol arms, respectively, whereas it was unchanged $(0.1 \%$ improvement) in the ramipril plus bisoprolol arm.

Meaning The results of this trial suggest that during cardiotoxic therapy for breast cancer, the use of pharmacological cardioprevention may be warranted.

months (T1), 6 months (T2), 12 months (T3, end of treatment [EOT]), and 24 months (T4, end of study) from enrollment. This was a prespecified interim analysis on the first 174 patients who had completed cardiac assessment at $\mathrm{T} 3$ and reached the EOT. Eighty-eight patients were not included in this analysis because they had not reached yet the 24-month follow-up (Figure 1). Patient selection (eMethods 1 in Supplement 2), chemotherapy regimens (eTable 1 in Supplement 2), cardiac assessment (eMethods 2 in Supplement 2), and statistics (eMethods 3 in Supplement 2) are reported. Statistical analyses were conducted using SPSS, version 26. 0 (IBM); statistical significance was set at 2 -side $a=.05$.

\section{Results}

Between July 2015 and June 2020, 262 patients were enrolled in the trial and randomized (Figure 1). The median age was 48 years (range, $24-75$ years), and most patients were stage I to II (143 [82.2\%]) and hormonal receptor-positive (132 [75.9\%]). Adjuvant trastuzumab was administered for $64 \mathrm{pa}-$ tients (36.8\%) and radiotherapy for 101 patients (58\%). No significant differences were found in group distribution, although there were more hormonal receptor-positive patients in the placebo (36 [86\%]) rather than ramipril plus bisoprolol

Figure 1. Consolidated Standards of Reporting Trials Diagram of the SAFE Trial

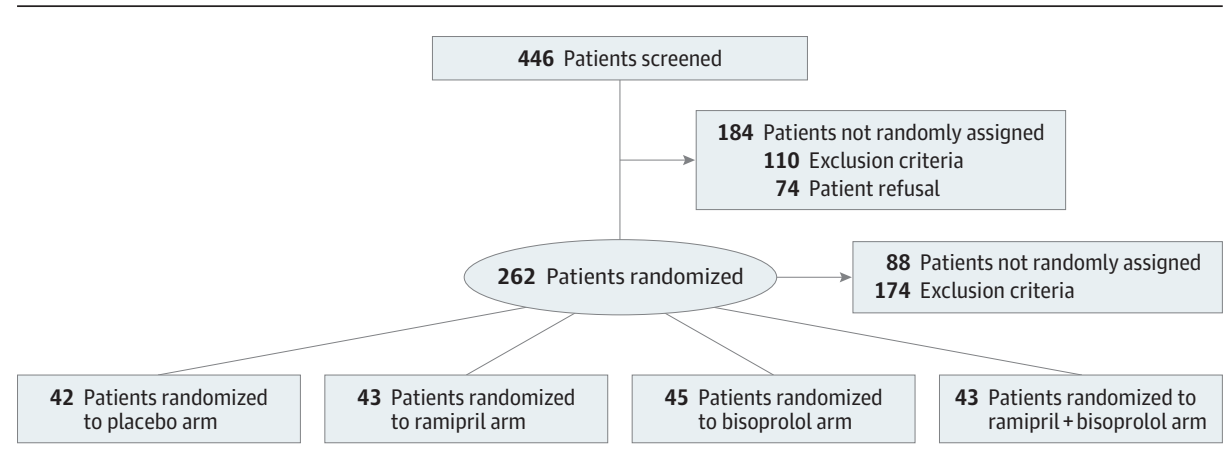

This preplanned analysis included first 174 patients who reached the end of treatment assessment. 


\begin{tabular}{|c|c|c|c|c|c|c|}
\hline \multirow[b]{3}{*}{ Arm } & \multirow[b]{3}{*}{ EOT, No. } & \multicolumn{4}{|l|}{ Mean $(95 \% \mathrm{Cl})$} & \multirow{3}{*}{$\begin{array}{l}\% \text { Changes } \\
\text { in EOT } \\
\text { vs baseline }\end{array}$} \\
\hline & & \multirow[b]{2}{*}{ Baseline unadjusted } & \multicolumn{3}{|l|}{ Adjusted } & \\
\hline & & & $3 \mathrm{Mo}$ & $6 \mathrm{Mo}$ & EOT & \\
\hline \multicolumn{7}{|l|}{ 3D-LVEF, \% } \\
\hline Placebo & 42 & $67.3(66.0$ to 68.5$)$ & 64.1 (63.3 to 64.9$)$ & $63.0(62.0$ to 64.0$)$ & $63.5(62.5$ to 64.5$)$ & -4.4 \\
\hline Ramipril & 44 & 65.7 (64.7 to 66.7$)$ & 65.4 (64.6 to 66.2 ) & $65.0(64.0 \text { to } 65.9)^{\mathrm{b}}$ & 64.4 (63.4 to 65.5$)$ & -3.0 \\
\hline Bisoprolol & 45 & $66.5(65.2$ to 67.7$)$ & $65.5(64.7$ to 66.3$)$ & $65.1(64.2 \text { to } 66.1)^{\mathrm{b}}$ & $65.2(64.2$ to 66.2$)$ & -1.9 \\
\hline Ramipril plus bisoprolol & 43 & $66.4(65.5$ to 67.4$)$ & $65.9(65.1 \text { to } 66.7)^{b}$ & $64.9(64.0 \text { to } 65.9)^{\mathrm{b}}$ & $65.6(64.6 \text { to } 66.6)^{b}$ & -1.3 \\
\hline All & 174 & 66.5 (65.9 to 67.0$)$ & NA & NA & NA & NA \\
\hline \multicolumn{7}{|l|}{ GLS } \\
\hline Placebo & 42 & $-24.1(-24.7$ to -23.5$)$ & $-22.2(-22.7$ to -21.8$)$ & $-21.8(-22.3$ to -21.3$)$ & $-22.0(-22.6$ to -21.4$)$ & -6.0 \\
\hline Ramipril & 44 & $-23.1(-23.5$ to -22.6$)$ & $-22.9(-23.3$ to -22.5$)$ & $-22.8(-23.2 \text { to }-22.3)^{\mathrm{b}}$ & $-23.0(-23.6$ to -22.5$)$ & -1.5 \\
\hline Bisoprolol & 45 & $-23.3(-23.9$ to -22.6$)$ & $-23.0(-23.4$ to -22.6$)$ & $-23.0(-23.5 \text { to }-22.5)^{c}$ & $-23.2(-23.8 \text { to }-22.7)^{b}$ & -0.6 \\
\hline Ramipril plus bisoprolol & 43 & $-23.0(-23.6$ to -22.4$)$ & $-23.5(-23.9 \text { to }-23.1)^{c}$ & $-23.1(-23.6 \text { to }-22.6)^{c}$ & $-23.4(-23.9 \text { to }-22.8)^{c}$ & 0.1 \\
\hline All & 174 & $-23.4(-23.6$ to -23.1$)$ & NA & NA & NA & NA \\
\hline \multicolumn{7}{|l|}{ EDVI, $\mathrm{mL} / \mathrm{m}^{2}$} \\
\hline Placebo & 42 & $52.4(50.0$ to 54.8$)$ & $56.6(55.6$ to 57.7$)$ & $58.0(56.6$ to 59.3$)$ & $58.6(57.1$ to 60.0$)$ & 11.3 \\
\hline Ramipril & 44 & 52.3 (49.6 to 55.0$)$ & $54.7(53.7 \text { to } 55.7)^{\mathrm{b}}$ & $55.0(53.7 \text { to } 56.3)^{\mathrm{b}}$ & $54.3(52.9 \text { to } 55.8)^{d}$ & 3.2 \\
\hline Bisoprolol & 45 & 53.5 (50.6 to 56.5$)$ & $52.6(51.6 \text { to } 53.6)^{d}$ & $52.5(51.2 \text { to } 53.8)^{d}$ & $53.2(51.8 \text { to } 54.6)^{d}$ & 1.0 \\
\hline Ramipril plus bisoprolol & 43 & $52.3(50.2$ to 54.3$)$ & $52.2(51.2 \text { to } 53.2)^{d}$ & $52.8(51.4 \text { to } 54.1)^{d}$ & $52.6(51.2 \text { to } 54.1)^{d}$ & 0.0 \\
\hline All & 174 & 52.7 (51.4 to 53.9$)$ & NA & NA & NA & NA \\
\hline \multicolumn{7}{|l|}{ ESVI, $\mathrm{mL} / \mathrm{m}^{2}$} \\
\hline Placebo & 42 & 17.2 (16.1 to 18.4$)$ & 20.2 (19.7 to 20.8) & 21.6 (20.9 to 22.4$)$ & 21.7 (20.8 to 22.7 ) & 23.0 \\
\hline Ramipril & 44 & 18.0 (16.8 to 19.1$)$ & $18.8(18.3 \text { to } 19.4)^{\mathrm{c}}$ & $19.2(18.5 \text { to } 19.9)^{d}$ & $19.1(18.2 \text { to } 20.0)^{c}$ & 8.4 \\
\hline Bisoprolol & 45 & 17.9 (16.8 to 19.1$)$ & $18.2(17.6 \text { to } 18.7)^{d}$ & $18.4(17.7 \text { to } 19.0)^{d}$ & $18.6(17.7 \text { to } 19.5)^{d}$ & 5.1 \\
\hline Ramipril plus bisoprolol & 43 & 17.6 (16.7 to 18.4$)$ & $17.8(17.3 \text { to } 18.4)^{d}$ & $18.5(17.7 \text { to } 19.2)^{d}$ & $18.1(17.2 \text { to } 19.0)^{d}$ & 2.3 \\
\hline All & 174 & 17.7 (17.1 to 18.2 ) & NA & NA & NA & NA \\
\hline \multicolumn{7}{|l|}{$E / A$} \\
\hline Placebo & 42 & 1.2 (1.1 to 1.2$)$ & 1.1 (1.0 to 1.2$)$ & 1.1 (1.0 to 1.1$)$ & 1.1 (1.0 to 1.2$)$ & -6.6 \\
\hline Ramipril & 44 & $1.2(1.1$ to 1.3$)$ & 1.2 (1.1 to 1.2$)$ & 1.1 (1.0 to 1.2$)$ & $1.2(1.1$ to 1.3$)$ & 0.1 \\
\hline Bisoprolol & 45 & $1.2(1.1$ to 1.3$)$ & $1.3(1.3 \text { to } 1.4)^{c}$ & $1.2(1.1 \text { to } 1.3)^{b}$ & $1.3(1.2 \text { to } 1.4)^{\mathrm{e}}$ & 12.8 \\
\hline Ramipril plus bisoprolol & 43 & $1.2(1.1$ to 1.2$)$ & $1.3(1.2 \text { to } 1.4)^{\mathrm{b}}$ & $1.3(1.2 \text { to } 1.3)^{c}$ & $1.3(1.2 \text { to } 1.4)^{\mathrm{e}}$ & 13.7 \\
\hline All & 174 & $1.2(1.1$ to 1.2$)$ & NA & NA & NA & NA \\
\hline \multicolumn{7}{|l|}{$\bar{E} / \mathrm{e}^{\prime}$} \\
\hline Placebo & 42 & 7.5 (6.9 to 8.0$)$ & 7.7 (7.3 to 8.1$)$ & $8.0(7.6$ to 8.5$)$ & $7.9(7.4$ to 8.3$)$ & 6.9 \\
\hline Ramipril & 44 & 7.2 (6.8 to 7.6$)$ & 7.2 (6.8 to 7.6$)$ & $7.7(7.2$ to 8.1$)$ & 7.7 (7.3 to 8.2$)$ & 4.9 \\
\hline Bisoprolol & 45 & $7.6(7.0$ to 8.1$)$ & 8.1 (7.7 to 8.5$)$ & 8.1 (7.7 to 8.6$)$ & 8.1 (7.6 to 8.5$)$ & 9.7 \\
\hline Ramipril plus bisoprolol & 43 & $7.2(6.7$ to 7.6$)$ & $7.6(7.2$ to 8.0$)$ & 7.8 (7.3 to 8.2$)$ & $7.9(7.4$ to 8.4$)$ & 7.5 \\
\hline All & 174 & $7.3(7.1$ to 7.6$)$ & NA & NA & NA & NA \\
\hline \multicolumn{7}{|l|}{$\mathrm{LAV}, \mathrm{mL} / \mathrm{m}^{2}$} \\
\hline Placebo & 42 & 24.5 (22.7 to 26.2$)$ & 24.6 (22.8 to 26.3$)$ & 26.5 (24.7 to 28.2 ) & $24.3(22.5$ to 26.1$)$ & 3.2 \\
\hline Ramipril & 44 & 24.1 (22.6 to 25.5$)$ & 24.8 (23.1 to 26.5$)$ & 24.1 (22.4 to 25.8$)$ & 22.1 (20.4 to 23.9$)$ & -6.0 \\
\hline Bisoprolol & 45 & $23.0(21.3$ to 24.7$)$ & 27.7 (26.0 to 29.4$)$ & 27.1 (25.4 to 28.8$)$ & 25.1 (23.4 to 26.8$)$ & 6.5 \\
\hline Ramipril plus bisoprolol & 43 & 22.7 (21.3 to 24.2$)$ & 25.1 (23.3 to 26.8$)$ & 24.4 (22.6 to 26.1$)$ & $24.0(22.2$ to 25.7$)$ & 1.8 \\
\hline All & 174 & 23.6 (22.8 to 24.3$)$ & NA & NA & NA & NA \\
\hline \multicolumn{7}{|l|}{$\mathrm{SAP}, \mathrm{mm} \mathrm{Hg}$} \\
\hline Placebo & 42 & 123 (119 to 126$)$ & 118 (115 to 121$)$ & 123 (120 to 126$)$ & 122 (119 to 126$)$ & -0.7 \\
\hline Ramipril & 44 & 124 (121 to 128$)$ & 117 (113 to 120$)$ & 117 (114 to 120$)$ & 119 (115 to 122$)$ & -3.7 \\
\hline Bisoprolol & 45 & 121 (117 to 124$)$ & 116 (112 to 120$)$ & 118 (115 to 121$)$ & $120(117$ to 123$)$ & -2.6 \\
\hline Ramipril plus bisoprolol & 43 & 125 (121 to 129$)$ & 113 (109 to 119$)$ & $111(108 \text { to } 114)^{d}$ & $115(112 \text { to } 119)^{\mathrm{b}}$ & -6.6 \\
\hline All & 174 & 123 (121 to 125$)$ & NA & NA & NA & NA \\
\hline
\end{tabular}




\begin{tabular}{|c|c|c|c|c|c|c|}
\hline \multirow[b]{3}{*}{ Arm } & \multirow[b]{3}{*}{ EOT, No. } & \multicolumn{4}{|l|}{ Mean $(95 \% \mathrm{Cl})$} & \multirow{3}{*}{$\begin{array}{l}\% \text { Changes } \\
\text { in EOT } \\
\text { vs baseline }\end{array}$} \\
\hline & & \multirow[b]{2}{*}{ Baseline unadjusted } & \multicolumn{3}{|l|}{ Adjusted } & \\
\hline & & & $3 \mathrm{Mo}$ & $6 \mathrm{Mo}$ & EOT & \\
\hline \multicolumn{7}{|l|}{ DAP, $\mathrm{mm} \mathrm{Hg}$} \\
\hline Placebo & 42 & 72.7 (70.0 to 75.3 ) & 71.8 (69.5 to 74.0$)$ & 75.2 (73.0 to 77.5$)$ & 74.2 (71.4 to 76.9$)$ & 0.7 \\
\hline Bisoprolol & 45 & $72.6(72.8$ to 78.3$)$ & 70.1 (67.8 to 72.3$)$ & 71.7 (69.5 to 73.9$)$ & 74.9 (72.1 to 77.6$)$ & 1.7 \\
\hline Ramipril & 44 & $75.6(70.0$ to 75.2$)$ & 69.8 (67.7 to 72.0$)$ & $71.2(69.0$ to 73.3$)$ & 70.8 (68.1 to 73.5$)$ & -3.9 \\
\hline Ramipril plus bisoprolol & 43 & 73.8 (70.6 to 77.0$)$ & $66.9(64.7 \text { to } 69.1)^{c}$ & $68.6(66.4$ to 70.8$)$ & 70.4 (67.6 to 73.1$)$ & -4.5 \\
\hline All & 174 & 73.7 (72.3 to 75.0$)$ & NA & NA & NA & NA \\
\hline \multicolumn{7}{|l|}{ Heart rate, bpm } \\
\hline Placebo & 42 & 71.5 (68.5 to 74.6$)$ & 80.0 (77.0 to 82.9$)$ & 81.3 (77.9 to 84.6$)$ & $72.2(69.2$ to 75.1$)$ & -1.0 \\
\hline Ramipril & 44 & 74.5 (71.1 to 77.8$)$ & 79.1 (76.2 to 82.0$)$ & 78.9 (75.5 to 82.2) & $70.0(67.1$ to 72.8$)$ & -4.0 \\
\hline Bisoprolol & 45 & $72.9(69.7$ to 76.0$)$ & $65.0(62.1 \text { to } 67.8)^{d}$ & $66.0(62.7 \text { to } 69.2)^{d}$ & $60.6(57.7 \text { to } 63.4)^{d}$ & -16.9 \\
\hline Ramipril - bisoprolol & 43 & 72.6 (68.6 to 76.6$)$ & $66.9(64.0 \text { to } 69.8)^{d}$ & $68.8(65.5 \text { to } 72.1)^{d}$ & $64.8(61.9 \text { to } 67.7)^{c}$ & -11.0 \\
\hline All & 174 & $72.9(71.2$ to 74.5$)$ & & & & \\
\hline
\end{tabular}

Abbreviations: 3D-LVEF, 3-dimensional left ventricular ejection fraction; bpm, beats per minute; DAP, diastolic arterial pressure; E/A, early to late diastolic transmitral flow velocity ratio; E/e', early diastolic transmitral flow velocity to early diastolic mitral annular tissue velocity ratio; EDVI, indexed left ventricular end diastolic volume; EOT, end of allocated treatment; ESVI, indexed left ventricular end systolic volume; GLS, global longitudinal strain; LAV, left atrial volume; SAP, systolic arterial pressure.

a Analysis was performed by analysis of covariance; covariates were compared by Bonferroni adjustment vs placebo.

${ }^{\mathrm{b}} P<.05$ compared with placebo arm.

${ }^{c} P<.005$ compared with placebo arm.

${ }^{\mathrm{d}} P<.001$ compared with placebo arm.

${ }^{\mathrm{e}} P<.01$ compared with placebo arm.
(30 [70\%]) arm $(P=.74)$. Patient baseline characteristics are summarized in eTable 2 in Supplement 2.

Cardiac features stratified by treatment-arm at each point are reported in eTable 3 in Supplement 2. The study drug hemodynamic effect as stratified by treatment arm and estimated changes from baseline to EOT using analysis of covariance are summarized in the Table. At 12 months, 3D LVEF worsened by $4.4 \%$ in the placebo arm and 3.0\%, $1.9 \%$, and $1.3 \%$ in the ramipril, bisoprolol, and ramipril plus bisoprolol arms, respectively $(P=.01)$. Global longitudinal strain worsened by $6.0 \%$ in placebo arm and $1.5 \%$ and $0.6 \%$ in the ramipril and bisoprolol arms, respectively, whereas was unchanged ( $0.1 \%$ improvement) in the ramipril plus bisoprolol arm $(P<.001)$. The number of patients whose 3D LVEF worsened by $10 \%$ or greater was $8(19 \%)$ in the placebo arm, 5 (11.5\%) in the ramipril arm, 5 (11.4\%) in the bisoprolol arm, and $3(6.8 \%)$ in the ramipril plus bisoprolol arm; 15 patients $(35.7 \%)$ who received placebo showed a $10 \%$ or greater worsening of GLS compared with 7 (15.9\%; ramipril), 6 (13.6\%; bisoprolol), and 6 (13.6\%; ramipril plus bisoprolol) $(P=.03)$.

Patients in a bisoprolol-containing arm exhibited a more favorable cardiac profile than those in the ramiprilcontaining arms, as showed by changes in 3D LVEF and GLS from baseline to 12 months (eTable 4 in Supplement 2) that were independent of patient- and treatment-related characteristics (Figure 2). End-diastolic volume (EDVI) and endsystolic volume (ESVI) values significantly favored patients in bisoprolol- and ramipril-containing arms compared with the placebo arm, especially in bisoprolol-containing arms.
A total of 125 patients reached the end of the study at T4 assessment (eTable 5 in Supplement 2). Compliance with the study drugs was good overall, although patients who received ramipril plus bisoprolol experienced higher dose titration (8 [18.6\%]) and a higher rate of hypotension (6 [14\%]) and cough (2 [4.7\%]) compared with other arms $(P<.05)$. Details are summarized in eTable 6 in Supplement 2 .

\section{Discussion}

To our knowledge, this study is one of the largest published series of homogenously treated patients who received a cardioprotective strategy who were assessed at 12 - and 24-month follow up using 3D LVEF and GLS as subclinical heart functional assessment. This study reinforced the importance of a cardioprotective strategy for early patients with BC who received an anthracycline-based chemotherapy. Ramipril and bisoprolol seemed to attenuate anthracycline-related decline in LVEF with a good safety profile, and the benefit was maintained at 12 and 24 months for most patients independently of patient-, cancer-, and treatment-related features. Women in the placebo arm showed adverse cardiac remodeling and decline in cardiac performance at 12 and 24 months. Conversely, patients who received a cardioprevention strategy using ramipril and/or bisoprolol showed a significant protective effect in terms of GLS and 3D LVEF values, notably favoring the bisoprololcontaining arms. It has been demonstrated that EDVI and ESVI might act as a surrogate for evaluating cardiac remod- 


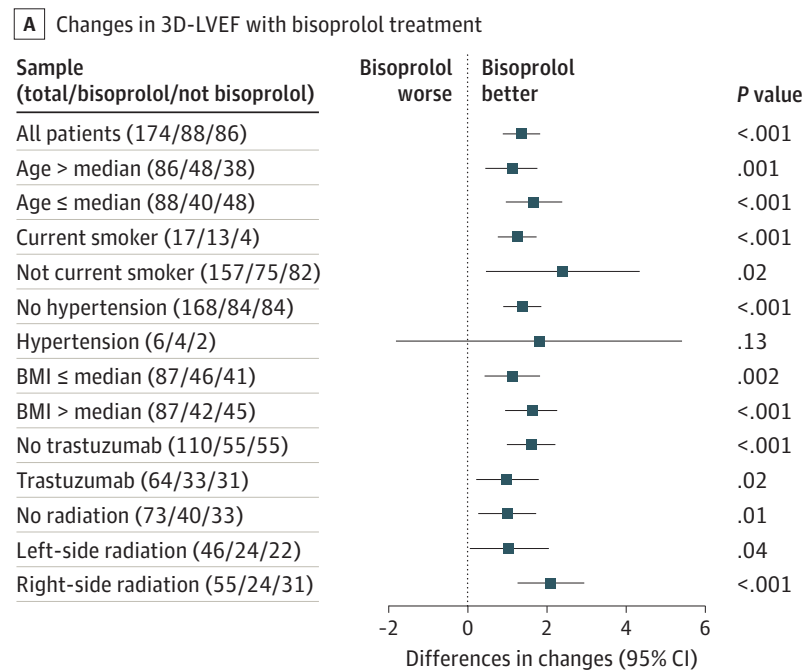

C Changes in GLS with bisoprolol treatment

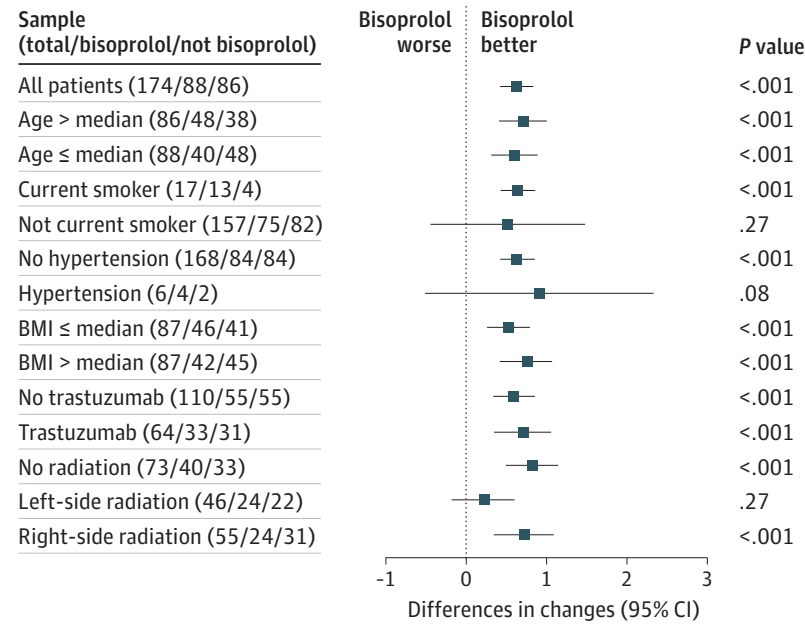

B Changes in 3D-LVEF with ramipril treatment Sample (total/ramipril/not ramipril) All patients (174/87/87) Age $>$ median $(88 / 43 / 45)$ Age $\leq$ median $(86 / 44 / 42)$ Current smoker (17/10/7) Not current smoker $(157 / 77 / 8)$

No hypertension (168/82/86) Hypertension (6/5/1) BMI $\leq$ median $(87 / 46 / 41)$ BMI > median $(87 / 41 / 46)$ No trastuzumab (110/56/54) Trastuzumab (64/21/33) No radiation (73/39/34) Left-side radiation $(46 / 18 / 28)$ Right-side radiation (55/30/25)

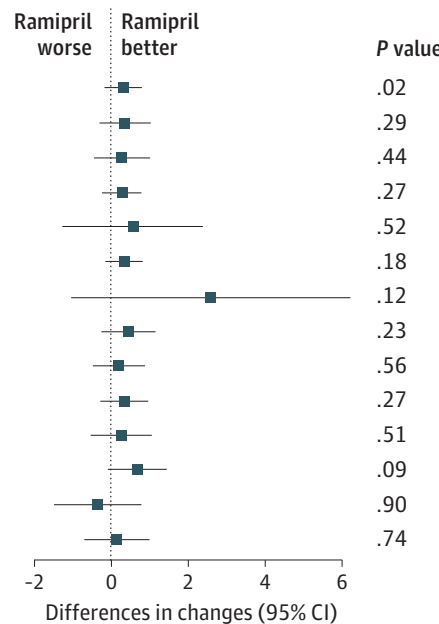

D Changes in GLS with ramipril treatment

Sample

(total/ramipril/not ramipril)

All patients (174/87/87)

Age $>$ median $(88 / 43 / 45)$

Age $\leq$ median (86/44/42)

Current smoker (17/10/7)

Not current smoker (157/77/80)

No hypertension (168/82/86)

Hypertension (6/5/1)

$\mathrm{BMI} \leq \operatorname{median}(87 / 46 / 41)$

BMI > median (87/41/46)

No trastuzumab (110/56/54)

Trastuzumab (64/21/33)

No radiation $(73 / 39 / 34)$

Left-side radiation (46/18/28)

Right-side radiation (55/30/25)

Changes from baseline to end of treatment in LVEF ( $A$ and B) and GLS (C and D) as expressed in percentage points with 95\% Cls. BMI indicates body mass index (calculated as weight in kilograms divided by height in meters squared).

eling. In patients who receive early diagnosis/intervention, cardiac function is more likely to recover with receipt of heart failure treatment. ${ }^{10}$

In this study, the protective effect of a cardioprevention was more evident at 12 months than at the end of active treatment. However, the benefit was maintained at 24 months for EDVI and ESVI, supporting the previously mentioned concept of a favorable effect on cardiac remodeling. In the MANTICORE trial, ${ }^{11} \mathrm{ACEi}$ and BB attenuated trastuzumab-mediated decline in LVEF without preventing heart remodeling.

In regard to 3D LVEF, all patient subgroups significantly benefitted from a bisoprolol-based therapy, whereas differences were not significant for those in ramipril-containing arms (Figure 2, A and B). In regard to GLS (Figure 2, C and D), all patients benefitted from bisoprolol-containing treatments.
To our knowledge, few studies have previously evaluated BB and ACEi alone or in combination to prevent myocardial dysfunction in patients who are receiving cardiotoxic therapies, although none of them evaluated GLS. ${ }^{12,13}$ Our data support the high sensitivity of GLS to identify subclinical damage and that cardiotoxic effects after anthracyclines occur within the first year after administration. ${ }^{14}$ The benefit related to a cardioprotective strategy was most evident in physically healthy and younger patients and patients without comorbidities, thus confirming that a cardioprotective strategy should be highly considered for all patients and not only for those classically considered at high risk. ${ }^{9}$ Conversely, the PRADA study (median follow-up, 23 months) showed that candesartan treatment was associated with a significant reduction in EDVI and only an attenuated decline in GLS and modest effect on LVEF at 2 years, suggesting that a cardioprotective 
approach may not be required in patients without preexisting cardiovascular disease. ${ }^{15}$

\section{Limitations}

This study had limitations. This was a preplanned interim analysis and the results, although significantly favoring a cardioprotective strategy, have to be confirmed at the final study analysis. Moreover, the slow rate of enrollment, worsened by the outbreak of COVID-19 that has severely affected the ability to safely conduct clinical trials, led to the prematurely termination of recruitment.

\section{Conclusions}

This preplanned interim analysis of the SAFE randomized clinical trial suggests that cardioprotective pharmacological strategies in patients who are affected by BC and receiving an anthracycline-based chemotherapy are overall well tolerated and seem to protect against LVEF decline and heart remodeling. Nevertheless, these encouraging preliminary results will have to be confirmed at the final results analysis.

\section{ARTICLE INFORMATION}

Accepted for Publication: June 7, 2021.

Published Online: August 26, 2021. doi:10.1001/jamaoncol.2021.3395

Author Affiliations: Department of Experimental and Clinical Biomedical Sciences, University of Florence, Florence, Italy (Livi, Desideri, Scotti, Becherini, Visani, Salvestrini, Mariotti, Meattini); Oncology Department, Careggi University Hospital, Florence, Italy (Livi, Desideri, Scotti, Becherini, Visani, Salvestrini, Mariotti, Meattini); Diagnostic Cardiology, Cardiothoracic, and Vascular Department, Careggi University Hospital, Florence, Italy (Barletta, Del Bene); Breast and Medical Oncology Units, Oncology Department, Azienda USL Toscana Centro, Florence, Italy (Martella, Bacci); Cancer Risk Factors and Lifestyle Epidemiology Unit, Institute for Cancer Research Prevention and Clinical Network, Florence, Italy (Saieva); Medical Oncology Unit 2, Città della Salute e della Scienza University Hospital, Turin, Italy (Airoldi, Pedani); Medical Oncology Unit, Ospedale Versilia, Lido di Camaiore, Lucca, Italy (Amoroso); Medical Oncology Unit, Livorno Hospital, Azienda USL Toscana Nord Ovest, Livorno, Italy (Coltelli); Breast Surgery Unit, Careggi University Hospital, Florence, Italy (Bernini, Sanchez, Orzalesi); Diagnostic Senology Unit, Careggi University Hospital, Florence, Italy (Nori); Division of Pathological Anatomy, Department of Health Sciences, University of Florence, Florence, Italy (Bianchi); Cardiomyopathy Unit, Careggi University Hospital, Florence, Italy (Olivotto).

Author Contributions: Drs Barletta and Livi had full access to all of the data in the study and take responsibility for the integrity of the data and the accuracy of the data analysis.

Concept and design: Livi, Barletta, Desideri, Airoldi, Visani, Salvestrini, Mariotti, Pedani, Meattini. Acquisition, analysis, or interpretation of data: Barletta, Martella, Saieva, Bacci, Del Bene, Amoroso, Coltelli, Scotti, Becherini, Visani, Salvestrini, Bernini, Sanchez, Orzalesi, Nori, Bianchi, Olivotto, Meattini.

Drafting of the manuscript: Livi, Barletta, Saieva, Del Bene, Airoldi, Amoroso, Coltelli, Becherini, Visani, Salvestrini, Mariotti, Pedani, Nori, Meattini. Critical revision of the manuscript for important intellectual content: Livi, Barletta, Martella, Desideri, Bacci, Scotti, Becherini, Visani, Salvestrini, Mariotti, Bernini, Sanchez, Orzalesi, Bianchi, Olivotto, Meattini.

Statistical analysis: Barletta, Saieva.

Obtained funding: Livi, Desideri, Meattini. Administrative, technical, or material support: Desideri, Bacci, Becherini, Visani, Bernini, Sanchez, Meattini.
Supervision: Livi, Barletta, Del Bene, Airoldi, Amoroso, Scotti, Becherini, Visani, Salvestrini, Mariotti, Pedani, Bernini, Orzalesi, Nori, Bianchi, Meattini.

Conflict of Interest Disclosures: Dr Olivotto reported grants from Myokardia, BMS, Shire, Takeda, Sanofi Genzyme, Amicus, and Bayer outside the submitted work. Dr Meattini reported personal fees from Novartis, Eli Lilly, Roche, and Pfizer outside the submitted work. No other disclosures were reported.

Additional Contributions: We thank the women enrolled in this trial, the study coinvestigators, and the staff of all the involved centers. We also thank Francesca Simontacchi (Fondazione Radioterapia Oncologica), Francesco Venditti, Giuseppe Pilato, Giorgio Galanti, Francesca Terziani, Noela Gori, Nicola Flego (Azienda Ospedaliero Universitaria Careggi), Roberto Tarquini (Empoli Hospital), Marco Di Lieto and Ilaria Pazzagli (Pistoia Hospita), Carmelo Bengala (Grosseto Hospital), Sara Donati (Versilia Hospital), Giacomo Allegrini (Livorno Hospital), Hector Jose Soto Parra (Azienda Ospedaliero Universitaria Policlinico), Giuseppe Curigliano (Istituto Europeo di Oncologia), and Valentina Guarneri (Istituto Oncologico Veneto) for their valuable contributions, for which they were not compensated.

Data Sharing Statement: See Supplement 3.

\section{REFERENCES}

1. Peto R, Davies C, Godwin J, et al; Early Breast Cancer Trialists' Collaborative Group. Comparisons between different polychemotherapy regimens for early breast cancer: meta-analyses of long-term outcome among 100,000 women in 123 randomised trials. Lancet. 2012;379(9814):432-444. doi:10.1016/S0140-6736(11)61625-5

2. Singal PK, Iliskovic N. Doxorubicin-induced cardiomyopathy. N Engl J Med. 1998;339(13):900905. doi:10.1056/NEJM199809243391307

3. Ewer MS, Lenihan DJ. Is trastuzumab associated with adverse cardiac effects in patients with breast cancer? Nat Clin Pract Oncol. 2008;5(4):192-193. doi:10.1038/ncponc1045

4. Wang SY, Long JB, Hurria A, et al. Cardiovascular events, early discontinuation of trastuzumab, and their impact on survival. Breast Cancer Res Treat. 2014;146 (2):411-419. doi:10.1007/s10549-014-3029-0

5. Plana JC, Galderisi M, Barac A, et al. Expert consensus for multimodality imaging evaluation of adult patients during and after cancer therapy: a report from the American Society of Echocardiography and the European Association of Cardiovascular Imaging. Eur Heart J Cardiovasc Imaging. 2014;15(10):1063-1093. doi:10.1093/ehjci/jeu192

6. Thavendiranathan P, Poulin F, Lim KD, Plana JC, Woo A, Marwick TH. Use of myocardial strain imaging by echocardiography for the early detection of cardiotoxicity in patients during and after cancer chemotherapy: a systematic review. J Am Coll Cardiol. 2014;63(25 pt A):2751-2768. doi:10.1016/j.jacc.2014.01.073

7. Oikonomou EK, Kokkinidis DG, Kampaktsis PN, et al. Assessment of prognostic value of left ventricular global longitudinal strain for early prediction of chemotherapy-induced cardiotoxicity: a systematic review and meta-analysis. JAMA Cardiol. 2019:4(10): 1007-1018. doi:10.1001/jamacardio.2019.2952

8. Ponikowski P, Voors AA, Anker SD, et al; ESC Scientific Document Group. 2016 ESC Guidelines for the diagnosis and treatment of acute and chronic heart failure: the task force for the diagnosis and treatment of acute and chronic heart failure of the European Society of Cardiology (ESC) developed with the special contribution of the Heart Failure Association (HFA) of the ESC. Eur Heart J. 2016;37(27):2129-2200. doi:10.1093/eurheartj/ehw128

9. Curigliano G, Lenihan D, Fradley M, et al; ESMO Guidelines Committee. Management of cardiac disease in cancer patients throughout oncological treatment: ESMO consensus recommendations. Ann Oncol. 2020;31(2):171-190. doi:10.1016/ j.annonc.2019.10.023

10. Kamphuis JAM, Linschoten M, Cramer MJ, Doevendans PA, Asselbergs FW, Teske AJ. Earlyand late anthracycline-induced cardiac dysfunction: echocardiographic characterization and response to heart failure therapy. Cardiooncology. 2020;6:23.

11. Pituskin E, Mackey JR, Koshman S, et al. Multidisciplinary Approach to Novel Therapies in Cardio-Oncology Research (MANTICORE 101-Breast): a randomized trial for the prevention of trastuzumab-associated cardiotoxicity. J Clin Oncol. 2017;35(8):870-877. doi:10.1200/JCO.2016.68.7830 12. Kalay N, Basar E, Ozdogru I, et al. Protective effects of carvedilol against anthracycline-induced cardiomyopathy. J Am Coll Cardiol. 2006;48(11): 2258-2262. doi:10.1016/j.jacc.2006.07.052

13. Cardinale D, Colombo A, Sandri MT, et al. Prevention of high-dose chemotherapy-induced cardiotoxicity in high-risk patients by angiotensin-converting enzyme inhibition. Circulation. 2006;114(23):2474-2481. doi:10.1161/ CIRCULATIONAHA.106.635144

14. Cardinale D, Colombo A, Bacchiani G, et al. Early detection of anthracycline cardiotoxicity and improvement with heart failure therapy. Circulation. 2015:131(22):1981-1988. doi:10.1161/ CIRCULATIONAHA.114.013777

15. Heck SL, Mecinaj A, Ree AH, et al. Prevention of Cardiac Dysfunction During Adjuvant Breast Cancer Therapy (PRADA) extended follow-up of a $2 \times 2$ factorial, randomized, placebo-controlled, double-blind clinical trial of candesartan and metoprolol. Circulation. 2021;143(25):2431-2440. doi:10.1161/CIRCULATIONAHA.121.054698 